\title{
Transcatheter occlusion of the patent ductus arteriosus with Cook detachable coils
}

Andrew J P Tometzki, Robert Arnold, Ian Peart, Narayanswami Sreeram, Jassim M Abdulhamed, Michael J Godman, Raman G Patel, Denise J Kitchiner, Frances A Bu'Lock, Kevin P Walsh

\begin{abstract}
Objective-To report initial experience with a new occlusion device for native and residual patent ductus arteriosus.

Design-Descriptive study of consecutive non-randomised patients undergoing a new method of patent ductus arteriosus closure with detachable coils.

Setting-Tertiary centres for paediatric cardiology.

Patients-71 consecutive patients, aged 1.2-22 years, with a patent ductus arteriosus (PDA) underwent elective transcatheter closure. 45 had native PDAs (group A) with a minimum diameter of $1.0 \mathrm{~mm}-5.0 \mathrm{~mm}$ (median $2.0 \mathrm{~mm}$ ). A further 26 had undergone one or more previous occlusion attempts (group B).

Interventions-A total of 133 detachable (Cook) spring coils were successfully implanted in 70 patients. The procedure was performed transvenously in 51 patients, retrograde arterially in 13 , and by both routes in a further 6 patients. One $5 \mathrm{~mm}$ coil migrated but was successfully retrieved.
\end{abstract}

Main outcome measures-In group A colour flow Doppler echocardiography showed that complete occlusion was achieved in $40 / 45(89 \%)$ at 24 hours, $41 / 45$ (91\%) at 1 month, and $44 / 45(98 \%)$ by 6 months post procedure. Occlusion rates in residual PDAs were $22 / 25(88 \%)$ occluded at 24 hours, $23 / 25(92 \%)$ at 1 month, and 24/25 (96\%) at 6 months follow up.

Conclusions-Transcatheter occlusion using detachable (Cook) spring coils is a safe and effective alternative to presently available devices. The delivery system allows full retrieval of the coil until a satisfactory position is obtained.

(Heart 1996;76:531-534)

M J Godman

Royal Manchester

Children's Hospital,

Manchester

R G Patel

Correspondence to:

Dr A Tometzki, Department

of Cardiology, Royal

Hospital for Sick Children,

Sciennes Road, Edinburgh

EH9 1LF.

Accepted for publication

7 July 1996

Keywords: ductus arteriosus; transcatheter occlusion; Cook spring coils; coils

Transcatheter implantation of the Rashkind double umbrella is a widely used treatment for patent ductus arteriosus (PDA) in children and adults. Residual shunts in $17 \cdot 5 \%$ to $38 \%$ of patients at one year are a cause of concern. ${ }^{1-4}$ Complications include embolisation of the device in $2 \cdot 1-15 \%$ of patients. ${ }^{1-3}$ Occlusion of the PDA with coils was first reported by Cambier et al in $1992 .{ }^{5}$ More recently techniques of single and multiple coil occlusion have been reported that use non-detachable Gianturco spring coils positioned either from the aorta or anterogradely through the pulmonary artery. ${ }^{67}$

We report our initial experience of a new technique for the implantation of detachable spring coils for PDA occlusion.

\section{Patients and methods}

PATIENTS

From September 1994 to October 199571 consecutive patients with PDA underwent elective closure through a transcatheter route. Median weight at cardiac catheterisation was $16.4 \mathrm{~kg}$ (range $7 \cdot 6$ to $61 \cdot 6 \mathrm{~kg}$ ) (age $1 \cdot 2-22$ years). Informed consent was obtained from all patients or their parents and the study was approved by the hospital's ethics committee. Forty five patients had native PDAs (group A) with a minimum diameter of $1.0 \mathrm{~mm}-5.0 \mathrm{~mm}$ (median $2.2 \mathrm{~mm}$ ). One child underwent implantation of a $12 \mathrm{~mm}$ Rashkind device during the study because a coil was not available. The umbrella embolised to the right pulmonary artery some hours after the procedure. This was successfully retrieved and coils were implanted during a second procedure. Twenty six patients had undergone one or more previous occlusion attempts (group B) 3-39 months previously with various techniques. Four patients had had two devices previously implanted and two had had surgical ligation. The patient data for groups $\mathrm{A}$ and $\mathrm{B}$ are presented in tables 1 and 2 respectively.

Table 1 Clinical data (median (range)) of 45 patients with native $P D A$ undergoing coil occlusion (group $A$ )

\begin{tabular}{ll}
\hline Data & Value \\
\hline M:F ratio & $14: 31$ \\
Age (yr) & $3 \cdot 75(1 \cdot 2-22)$ \\
Weight (kg) & $15 \cdot 5(7 \cdot 6-61 \cdot 6)$ \\
Minimum diameter of PDA (mm) & $2 \cdot 0(1-5)$ \\
Screening time (min) & $18 \cdot 9 \quad\left(5-127^{\star}\right)$ \\
\hline
\end{tabular}

${ }^{\star}$ Long screening time because of embolisation of coil. 
Table 2 Clinical data (median (range)) of $27^{\star}$ patients with residual PDA undergoing coil occlusion (group $B$ )

\begin{tabular}{lc}
\hline Data & Value \\
\hline M:F ratio & $6: 21$ \\
Age (yr) & $4 \cdot 6(1 \cdot 2-16 \cdot 9)$ \\
Weight (kg) & $18(9 \cdot 4-56 \cdot 6)$ \\
Minimum diameter of PDA (mm) & $1 \cdot 9(1 \cdot 0-3 \cdot 0)$ \\
Screening time (min) & $15 \cdot 0(2 \cdot 8-57 \cdot 0)$ \\
\hline
\end{tabular}

^Includes one patient from group $\mathrm{A}$

PDA, patent ductus arteriosus.

\section{PROCEDURE}

Sixty procedures were performed under general anaesthesia and 12 with sedation and local anaesthesia. A $5 \cdot 5$ to $7 \mathrm{~F}$ sheath was placed in the right femoral vein and a 4 or $5 \mathrm{~F}$ sheath in the left femoral artery. All patients received 50 to $100 \mathrm{U} / \mathrm{kg}$ heparin intravenously. Prophylactic antimicrobial treatment was given in the form of $30 \mathrm{mg} / \mathrm{kg}$ intravenous cefotaxime. Ductal morphology and size were assessed on a lateral aortogram. A 5 or $6 \mathrm{~F}$ Gensini or multipurpose catheter was passed transvenously across the duct into the descending aorta. A 5.5 or $6.3 \mathrm{~F}$ multipurpose end hole only (Cook) catheter was used to deliver the coils. If it was not possible to cross the PDA anterogradely then the duct was crossed by a retrograde arterial approach with a $4 \mathrm{~F}$ multipurpose (Microvena) catheter.
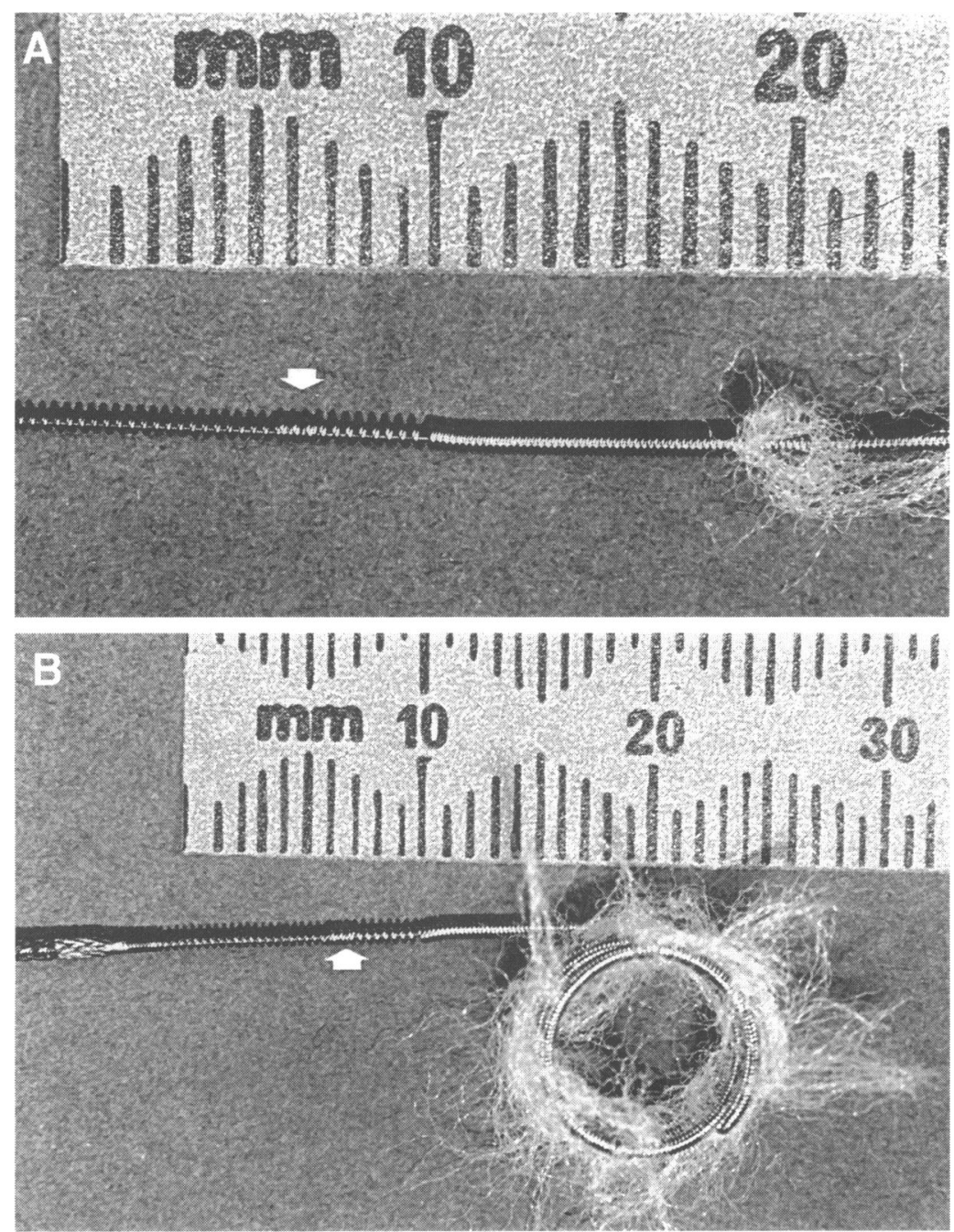

Figure 1 Spiral coil and delivery wire with $(A)$ mandril wire extended and $(B)$ mandril wire withdrawn and loops configured showing the locking mechanism (arrows).
DEVICE DESCRIPTION

The spring coils are manufactured from stainless steel and contain fibres of Dacron wool. The delivery mandril wire (TDS-110-PDA) is passed into the central lumen of the spring coil and not more than three clockwise turns are made to interlock the helical screw of the spring coil with an opposing screw on the delivery wire (fig 1). The mandril maintains the coil in a straight position during the insertion and advancement to the tip of the delivery catheter. The mandril is then withdrawn and the coil extruded until 2-4 loops form in the descending aorta. The whole catheter with the coil partly extruded is withdrawn into the ampulla of the duct and the remaining loop is then released on the pulmonary side of the duct. The coil is detached by making several anti-clockwise turns to the delivery wire. Until this manoeuvre is performed the coil remains fully retrievable. If angiography shows residual flow the duct is re-crossed with a guidewire and delivery catheter and a further coil implanted. In two patients a $5.5 \mathrm{~F}$ sheath was placed in the left femoral vein to facilitate the placement of a further coil(s) before the implanted coil was detached.

For conical ducts with a minimum diameter of $2 \mathrm{~mm}$ or more we use an $8 \mathrm{~mm}$ helical diameter coil as the first coil with either three or four loops. For small tubular PDAs $<2 \mathrm{~mm}$ in minimum diameter a $5 \mathrm{~mm}$ coil is employed usually with five loops. The $10 \mathrm{~cm}$ length by 8 $\mathrm{mm}$ diameter coil has four loops (MWCE-8PDA 4), three of which are positioned in the aortic ampulla and one loop passes through the duct into the pulmonary artery. After implantation of the first coil of $8 \mathrm{~mm}$ diameter, a further $8 \mathrm{~mm}$ diameter coil (usually $8 \mathrm{~cm}$ in length and three loops [MWCE-8-PDA-3]) is used if the minimum diameter of the duct is greater than $3 \mathrm{~mm}$. If, however, the minimum diameter of the duct is less than $3 \mathrm{~mm}$ then a 5 $\mathrm{mm}$ diameter coil (usually $8 \mathrm{~cm}$ length and five loops [MWCE-5-PDA-5]) is implanted as the second coil. Should a third coil prove necessary this is usually of $5 \mathrm{~mm}$ diameter and 5 $\mathrm{cm}$ in length (three loops [MWCE-5-PDA3]).

\section{FOLLOW UP}

Patients were discharged within 24 hours of the procedure after a repeat chest $x$ ray and an echocardiogram. Subsequently they were reviewed at one and six months with echocardiographic assessment.

\section{Results}

A total of 131 detachable coils were successfully implanted. The coils used were 5 to 12 $\mathrm{cm}$ in length and 5 to $8 \mathrm{~mm}$ in helical diameter. In all cases where a post-implantation angiogram revealed anything more than a trivial residual leak an attempt to re-cross the duct was made to enable further positioning of coils. Importantly, despite re-crossing a PDA with implanted coils, no coils embolised during this manoeuvre. However, a $5 \mathrm{~mm}$ coil embolised from a $2.5 \mathrm{~mm}$ duct in an 18 month 

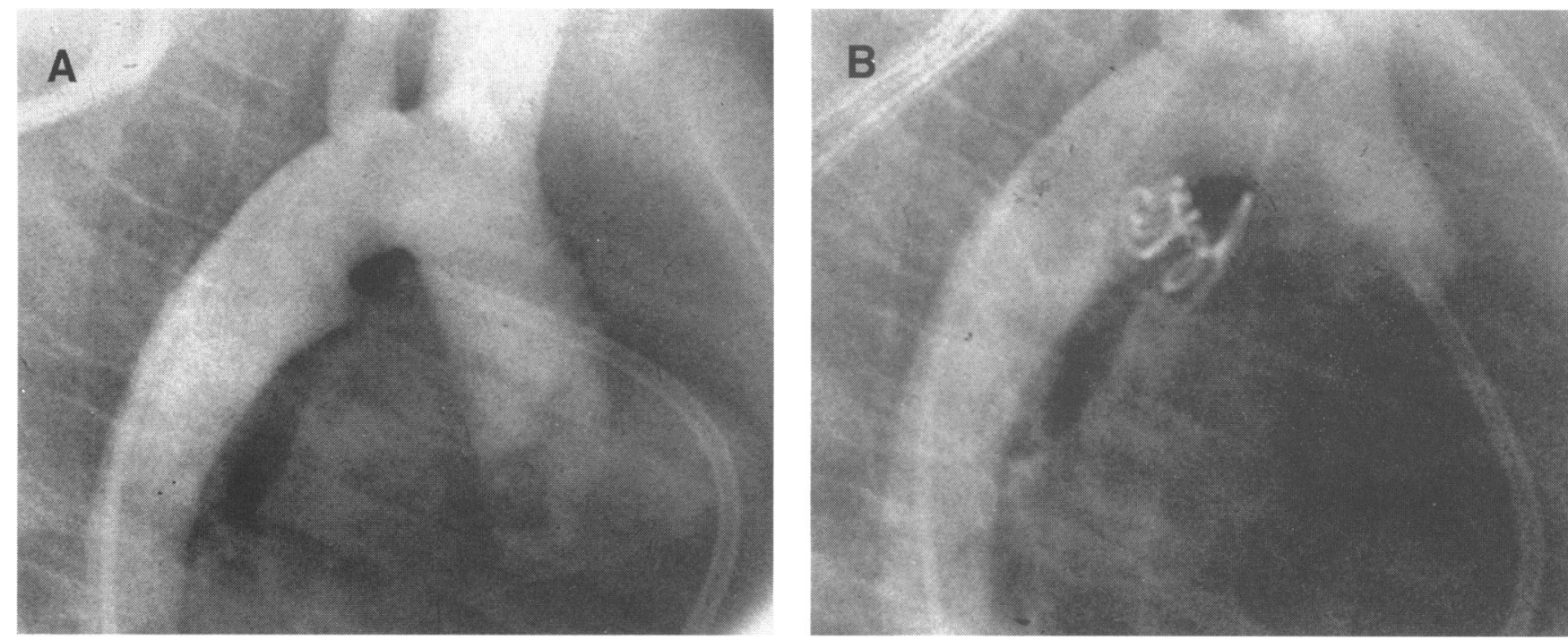

Figure 2 Lateral aortograms from a native PDA $(A)$ before and $(B)$ after implantation of two spring coils.

old patient in whom an initial $8 \mathrm{~mm} \times 4$ loop coil was removed because it protruded into the pulmonary artery. The embolised coil was retrieved and subsequently an $8 \mathrm{~mm} \times 3$ loop coil followed by a $5 \mathrm{~mm} \times 5$ loop coil were implanted.

GROUP A

Ten patients required a single coil whereas the remainder required multiple coils to produce a satisfactory angiographic result. Two coils were deployed (fig 2) in 20 patients (44\%), 11 $(24 \%)$ required three coils, and three $(7 \%)$ required four coils. One two year old child weighing $10.8 \mathrm{~kg}$ needed seven coils to achieve an on the table occlusion. In two cases the first coil was left attached to the delivery wire while the PDA was re-crossed with a guidewire. In five cases it was not possible to re-cross the PDA from the venous side and therefore a $4 \mathrm{~F}$ multipurpose catheter (Microvena) was used to re-cross the PDA, from the arterial side, to implant a second or subsequent coil. In six cases the duct required an arterial approach for coil implantation. An arteriovenous guidewire loop was set up to enable transvenous deployment in one patient.

Complete occlusion was achieved in $40 / 45$ $(89 \%)$ at 24 hours, $41 / 45(91 \%)$ at one month, and $44 / 45$ (98\%) by six months post procedure as assessed by colour flow Doppler echocardiography. One patient had a trivial residual leak on colour flow Doppler echocardiography six months after implantation.

\section{GROUP B}

In one patient it was not possible to cross the duct and the procedure was abandoned. An arterial approach was employed in eight patients. Seventeen $(68 \%)$ of 25 patients required a single coil to obtain closure at catheterisation. Two coils were implanted in a further seven patients (fig 3). A 30 month old child with an adjustable button device and a $17 \mathrm{~mm}$ Rashkind device already in situ required five coils to obtain angiographic occlusion because of multiple jets around the previous devices.

Twenty two (88\%) were completely occluded at 24 hours. All but one patient, with
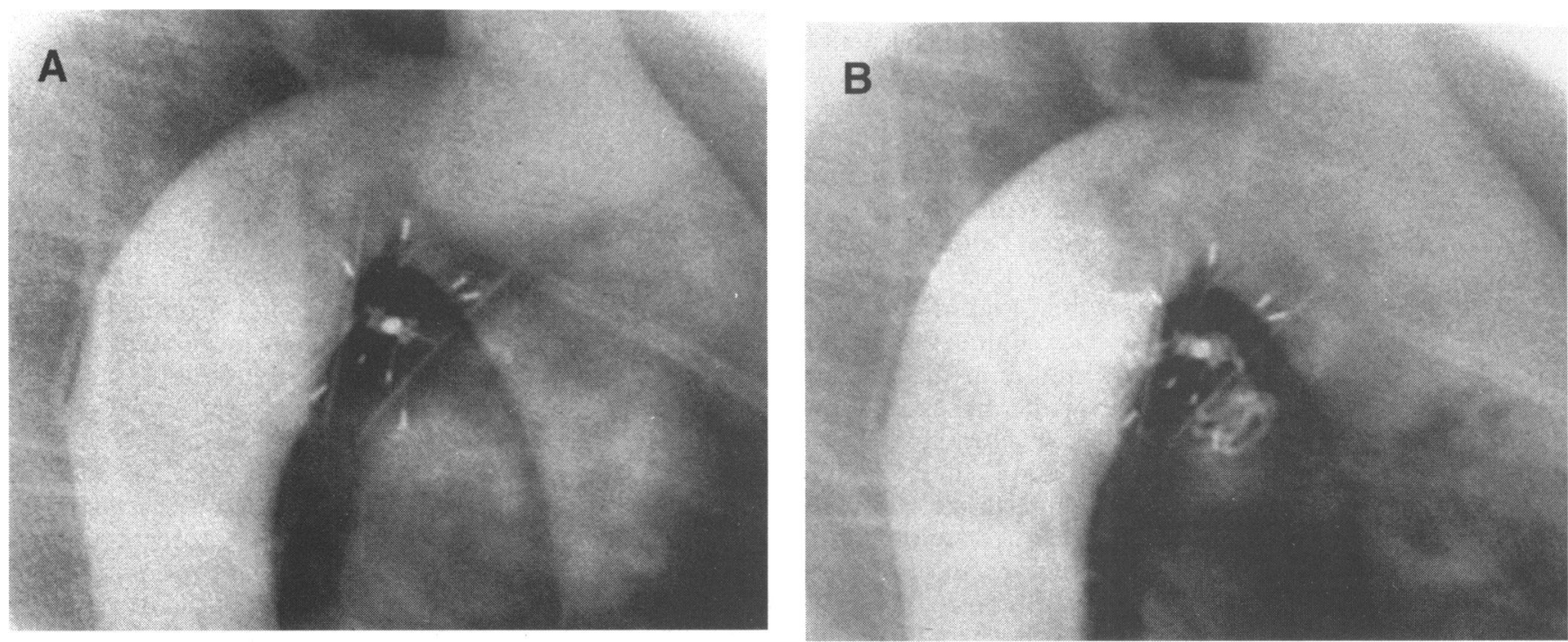

Figure 3 Lateral aortograms $(A)$ before and $(B)$ after implantation of two $5 \mathrm{~mm}$ spring coils used to treat a residual leak after implantation of a previous Rashkind umbrella device followed by a Sideris adjustable button. 
a previous $17 \mathrm{~mm}$ Rashkind device and a single $5 \mathrm{~mm}$ coil, were occluded at six months follow up.

\section{PULMONARY ARTERY IMPINGEMENT}

We looked critically for Doppler evidence of left pulmonary artery (LPA) stenosis and found slightly increased velocities of $2 \cdot 0-2 \cdot 3$ $\mathrm{m} / \mathrm{s}$ in three cases from group A. One patient from group B had evidence at pre-procedural echocardiography and catheterisation of mild stenosis of the left pulmonary artery (LPA). No increase in LPA velocity was noted on repeat Doppler interrogation 24 hours after implantation of a coil. This patient had had a $17 \mathrm{~mm}$ Rashkind device implanted three years previously.

\section{COMPLICATIONS}

There were no clinical complications and only one coil embolisation. Seventeen coils were electively withdrawn, because of excessive protrusion into either the aorta or pulmonary artery, without difficulty before release. Inability to detach the coil from the delivery wire occurred on three occasions. Difficulty with coil release was encountered in seven cases, necessitating additional anti-clockwise rotations of the delivery wire. This may have been due to over-engaging the helical screw mechanism. We recommend no more than three clockwise turns to engage the coil on the delivery system.

\section{COST ISSUES}

We calculate that in our unit the cost differential between this and other devices for PDA occlusion relates almost exclusively to materials because the procedure times were similar. The Rashkind device costs $£ 2300$, whereas three coils plus a delivery system costs about $£ 300$.

\section{Discussion}

COMPARISON WITH THE RASHKIND DOUBLE UMBRELLA DEVICE

The widely used Rashkind double umbrella device requires two operators and a large delivery catheter of 8 or $11 \mathrm{~F}$ diameter. In contrast the detachable coil delivery system is smaller and can be easily assembled by a single operator. Residual shunting after closure with a Rashkind device is common..$^{1-4}$ In one case in our series a previously sealed duct recanalised after implantation of a $17 \mathrm{~mm}$ device: a similar case was reported by others. ${ }^{8}$ The early occlusion rate with the detachable coil system seems to be better than that of the Rashkind double umbrella device. Our series includes 35 native PDAs with minimum diameters of $3 \mathrm{~mm}$ or less. These would be expected to achieve a good long-term occlusion rate with the $12 \mathrm{~mm}$ diameter Rashkind double umbrella. Subsequent endothelialisation of the umbrella device will produce complete occlusion in about $90 \%$; however, this may take up to three years. Khan et al reported that at least $10 \%$ of patients with Rashkind double umbrella implants required a second device for residual continuous murmurs. ${ }^{9}$

\section{COMPARISON WITH CONVENTIONAL COIL}

\section{OCCLUSION}

Coil occlusion of the PDA has been performed previously with good results by advancing them, unattached, through a delivery catheter. ${ }^{67}$ Embolisation to the branch pulmonary arteries has been a problem and in some patients catheter retrieval has not been possible and the embolised coils have been left in place. ${ }^{6}$ It is therefore important to be able to retrieve the device intact up until the point where one is completely satisfied with its position. In our series there was one coil embolisation $(1 \cdot 4 \%)$ compared with $9 \%$ experienced when conventional coils were used. ${ }^{7} \mathrm{We}$ attribute our low rate to the controlled release mechanism.

Unlike others who have implanted multiple conventional coils we did not pass a second guidewire before we deployed the first coil. ${ }^{7}$ However, the first coil was left attached to the delivery wire while the PDA was re-crossed in two patients in our series. This probably made the procedure unnecessarily complex. Multiple coils are required for complete occlusion in most cases with a native PDA. No patient in group $A$ with three or more coils had a residual shunt at 24 hours.

\section{TREATMENT OF RESIDUAL DEVICE LEAKS}

This technique provides effective occlusion for residual leaks after previously implanted Rashkind devices. Implantation of a second umbrella can be technically demanding, requiring either sequential dilatation, an extra stiff guidewire, or an arteriovenous guidewire loop.

\section{PATIENT SELECTION}

Our series contains 45 consecutive patients with native PDAs undergoing transcatheter occlusion. In no case did we opt to place a 17 $\mathrm{mm}$ diameter umbrella rather than coils. Because the coil technique requires a small delivery catheter it seems to be a suitable option in the treatment of PDAs in selected younger infants. Such infants often have a relatively large PDA with an increased potential of residual leaks and LPA stenosis. ${ }^{1011}$ Although it is technically possible to place multiple coils in these larger PDAs, because the patient is smaller there is a greater likelihood of significant protrusion into the left pulmonary artery and resulting stenosis. This has been shown to be the case by Hijazi et al who placed four and five coils in two patients weighing 3.4 and $5 \mathrm{~kg}$ respectively, resulting in significant left pulmonary artery stenosis in both patients. ${ }^{7}$ We have restricted this technique to children over $8 \mathrm{~kg}$ in weight. Infants under this weight with a symptomatic PDA were referred for surgery.

A study of ductal anatomy by Krichenko $e t$ al showed that tubular (type C) ducts present particular difficulties in positioning an umbrella device. ${ }^{12}$ It is our belief that these concerns are not so important with a coil system which is able to configure more closely to the shape of the duct. 
COST ISSUES

Surgical ligation was recently reported to be more cost effective than transcatheter implantation of the Rashkind umbrella device. ${ }^{13}$ However, this study had some important flaws as highlighted by Tynan. ${ }^{14}$ The use of this new detachable (Cook) spring coil would provide significant savings on equipment costs compared with the Rashkind umbrella. In our unit, using two or three coils per patient, the cost saving is about $£ 2000$ per procedure. This we believe would reverse the cost analysis performed by Gray et al in favour of transcatheter occlusion. ${ }^{13}$

The detachable (Cook) spring coil technique offers a safe, controlled, and cost effective method of transvenous occlusion for paediatric patients with either a native or residual PDA. Despite multiple operators we have achieved a high occlusion rate $(98 \%$ for native and $96 \%$ for residual PDAs at six months follow up). Significant cost saving with increased efficacy is possible with this multiple coil occlusion technique. Although larger studies are required to explore its role more fully, we consider that transcatheter occlusion by multiple detachable spring coils is the treatment of choice in most patients with a PDA.

1 Hosking MCK, Benson LN, Musewe NM, Dyck JD, Freedom RM. Transcatheter occlusion of the patently Freedom RM. Transcatheter occlusion of the patently
patent ductus arteriosus. Forty month follow-up and prevalence of residual shunting. Circulation 1991;84 2313-7.

2 Latson LA. Residual shunts after transcatheter closure of the patent ductus arteriosus. A major concern or benign "Techno-malady". Circulation 1991;84:2591-3.

3 Report of the European Registry. Transcatheter occlusion of persistent arterial duct. Lancet 1992;240:1062-6.

4 Rashkind WJ, Mullins CE, Hellenbrand WE, Tait MA Non-surgical closure of patent ductus arteriosus: clinical application of the Rashkind PDA occluder device. application of the Rashkind
Circulation 1987;75:583-92.

5 Cambier PA, Kirby WC, Wortham DC, Moore JW. Percutaneous closure of the small $(>2 \cdot 5)$ patent ductus arteriosus using coil embolization. Am $\mathcal{f}$ Cardiol 1992; 69:815-6.

6 Moore JW, George L, Kirkpatrick SE, Matheswson JW, Spicer RL, Uzark K, et al. Percutaneous closure of the small ductus arteriosus using occluding coil springs. $f \mathrm{Am}$ Coll Cardiol 1994;23:759-65.

7 Hijazi Z, Geggel RL. Results of antegrade transcatheter closure of patent ductus arteriosus using single or multiple coils. Am $尹$ Cardiol 1994;74:925-9.

8 Bjornstad PG, Smevik B. Recanalization of the arterial duct after initial total occlusion with the Rashkind umbrella. Cardiol Young 1995;5:98-9.

9 Khan MA, al-Yousef S, Mullins CE, Sawyer W. Experience with 205 procedures of transcatheter closure of ductus arteriosus in 182 patients, with special referof ductus arteriosus in 182 patients, with special refer-
ence to residual shunts and long term follow-up. 7 Thorac ence to residual shunts and long term
Cardiovasc Surg. 1992;104:1721-7.

10 Nykanen DG, Hayes AM, Benson LN, Freedom RM Transcatheter patent ductus arteriosus occlusion: application in the small child. $\mathcal{f} \mathrm{Am}$ Coll Cardiol 1994; 231:666-70

11 Gatzoulis MA, Rigby ML, Redington AN. Umbrella occlusion of the persistent arterial duct in children under two years. Br Heart $\mathcal{F}$ 1994;72:364-7.

12 Krichenko A, Benson LN, Burrows P, Moes CAF Mclaughlin P, Freedom RM. Angiographic classification of the isolated, persistently patent ductus arteriosus and implications for percutaneous catheter occlusion. $A m$ Cardiol 1989;67:877-80.

13 Gray DT, Fyler DC, Walker AM, Weinstein MC, Chalmers TC. Clinical outcomes and costs of transcatheter as compared with surgical closure of patent ductus arteriosus. $N$ Engl f Med 1993;329:1517-23.

14 Tynan $M$. The ductus arteriosus and its closure. $N$ Engl $f$ Med 1993;18:1571-2. 